\title{
FLUXO DE CAIXA: FERRAMENTA ESTRATÉGICA NA GESTÃO DE UMA MICROEMPRESA
}

\author{
Janete Fernandes Policarpo ${ }^{1}$ \\ Tarciana Borges Ferreira ${ }^{2}$
}

\section{RESUMO}

O presente artigo foi elaborado com o objetivo de propor o uso do fluxo de caixa em uma microempresa que se encontrava com problemas para se manter no mercado. Foi elaborado um fluxo de caixa que permitiu identificar um nível de recursos financeiros adequado para honrar compromissos de curto prazo, assim como planejar e controlar as entradas e saídas de caixa para pagamentos de médio prazo. Estas informações auxiliam na tomada de decisões e causam impactos positivos no lucro líquido da empresa. Este artigo é uma demonstração de que o fluxo de caixa é uma ferramenta eficaz de planejamento e controle quando utilizado como instrumento de gestão financeira.

Palavras-chave: Planejamento. Controle. Fluxo de Caixa.

Data de submissão: $22 / 02 / 2020$

Data de aprovação: $24 / 03 / 2020$

\section{INTRODUÇÃO}

Podemos observar o quanto a organização financeira de uma empresa - independente do seu porte - é fundamental para proporcionar ao empresário ou investidor uma visão que permite avaliar a disponibilidade e liquidez da empresa, facilitando na tomada de decisões e levando ao crescimento e estabilidade da mesma.

O uso e controle da ferramenta Fluxo de Caixa, se adequadamente utilizada, pode mapear a real situação financeira de uma empresa, auxiliando a reverter saldos negativos que podem levar a caminhos indesejados - como a falência, por exemplo - e a definir estratégias que culminem no crescimento empresarial.

Esperamos que este trabalho possa servir, no futuro, como ferramenta de apoio e pesquisa para os que tenham interesse pelo presente assunto.

1 Discente do curso de Ciências Contábeis da FMGR. E-mail: janfernandes.jf@gmail.com

2 Docente orientadora do curso de Ciências Contábeis da FMGR. E-mail: tarciana@metropolitana.edu.br 


\section{REFERENCIAL TEÓRICO}

O fluxo de caixa é uma ferramenta estratégica na gestão, pois, através dele, é possível realizar uma leitura analítica da situação da empresa e auxiliar no planejamento de curto, médio e longo prazo.

Ao contrário do que algumas pessoas pensam esta ferramenta não se resume ao uso de planilhas de entradas e saídas de valores e/ou mercadorias e serviços, apesar de ser um bom começo para uma leitura preliminar de um problema visível, como é o caso do empreendimento que será alvo desta pesquisa.

De forma geral, o fluxo de caixa é uma ferramenta administrativa que carrega em si a capacidade de gerar informações valiosas para auxiliar no desempenho de uma gestão financeira bem-sucedida, além de capacitar os gestores para a execução de um planejamento adequado e controle econômico da empresa, uma vez que, sendo utilizado adequadamente ao porte da empresa, é capaz de prever o rumo financeiro da mesma.

De acordo com Marion (2008), "[...] sem o fluxo de caixa fica quase impossível projetar e planejar-se financeiramente. Sem orçamento (planejamento financeiro) é impossível ter uma administração sadia [...]". Com isso, podemos entender que o fluxo de caixa é uma ferramenta indispensável para quem quer manter as contas em ordem. Por muitas vezes, o uso de uma simples planilha auxilia a elucidar o andamento cotidiano das contas, podendo ser considerado como um instrumento de controle.

Segundo dados do IBPT (Instituto Brasileiro de Planejamento e Tributação) existe um índice exorbitantemente alto de MEI's que finalizam suas funções em menos de um ano. A incapacidade de diferenciar lucro de caixa ainda é um fato relevante para levar uma empresa às situações indesejadas.

Este artigo tem como objetivo principal constatar, através de experimento real, a funcionalidade do fluxo de caixa como ferramenta de gestão e a possibilidade de, através do seu uso, identificar possíveis falhas administrativo-financeiras, auxiliando na tomada de decisões para mudança do cenário atual da empresa.

\section{Contextualização do Fluxo de Caixa}

A Lei 11.638, de 28 de dezembro de 2007, determinou a obrigatoriedade da elaboração da DFC - Demonstração do fluxo de caixa. Tal ferramenta contábil teve origem nos Estados Unidos. No Brasil, já se fazia uso de algo similar - DOAR (Demonstração das 
Origens e Aplicações de Recursos) - que, por motivos de simplificação para a compreensão dos investidores, foi substituída.

O fluxo de caixa, e a devida demonstração do mesmo, podem ser definidos da seguinte forma:

A DFC é um relatório contábil que tem por fim evidenciar as transações ocorridas em um determinado período e que provocaram modificações no saldo da conta Caixa. [...] Fluxos de Caixa, portanto, compreendem o movimento de entradas e saídas de dinheiro da empresa. (RIBEIRO, 2009, p. 396 - 397).

Segundo Gitman (2004), o fluxo de caixa pode ser visto como sendo a espinha dorsal da entidade empresária, ou seja, ele é quem nos informa se os recursos existentes serão suficientes para sustentar o peso das operações e, ainda, se e quando será necessário captar novos recursos.

Para Zdanowicz (2002), "o fluxo de caixa utiliza as seguintes contas: caixa, banco, aplicações financeiras de resgate imediato da empresa, ou seja, consiste no fluxo do disponível". Este mesmo autor conceitua o fluxo de caixa como sendo "um instrum ento que relaciona o futuro conjunto de ingressos e de desembolsos de recursos financeiros pela empresa em determinado período".

Na opinião de Santos (2001), o fluxo de caixa é um instrumento de planejamento financeiro que tem por finalidade fornecer estimativas da situação de caixa da empresa em determinado período de tempo à frente. A necessidade de planejamento de caixa está presente tanto nas empresas com dificuldades financeiras como naquelas bem capitalizadas.

Diante dessas definições, vemos que o fluxo de caixa é o registro do que se recebe e paga-se numa empresa. Assim, ao utilizar tal ferramenta, garantindo registros detalhados de entradas e saídas, sem erros, podemos ter uma visão diária, semanal e/ou mensal, servindo como um instrumento de verificação e análise para a empresa e, ainda, conferindo informações seguras e importantes sobre a saúde financeira da empresa, permitindo aos administradores a monitoração das movimentações de recursos presentes e futuros principalmente se esta for de pequeno porte.

Conforme afirma Matarazzo (1998), "muitas empresas vão à falência por não saber administrar seu fluxo de caixa”. Esta afirmação nos revela a eficácia e eficiência desta ferramenta como um instrumento de controle financeiro e a necessidade de acompanhar suas alterações, a fim de deter os possíveis problemas antes que eles apareçam, mantendo, desta forma, a estabilidade financeira da empresa. 
Antes de aprofundarmos nossa pesquisa, faz-se necessário informar que há diferentes tipos de fluxo de caixa, entre eles: os operacionais, de investimentos e os de financiamentos. Suas variações trazem diferentes visões da situação financeira da empresa.

Santi Filho (2004) afirma que as entradas e saídas de caixa classificadas nesses três grupos têm o somatório do resultado líquido de caixa das três atividades e deve ser igual ao aumento ou a redução líquida das disponibilidades.

\section{Fluxo de Caixa Operacional}

O Fluxo de Caixa Operacional, segundo Gitman (2004), é aquele que, basicamente, registra as entradas e saídas. Assim, está diretamente ligado à venda e à produção de bens e serviços.

As atividades operacionais são as principais geradoras de receita da empresa. Os fluxos de caixa que advém das atividades operacionais são derivados das principais atividades que geram receita para a empresa, sendo assim, geralmente são resultados de transações e de outros eventos que estão presentes quando se calcula o lucro líquido ou prejuízo da empresa. (CPC 03 R2, 2010).

Braga e Marques (2001) identificam as entra das de caixa como: (a) recebimentos de caixa das vendas de bens ou serviços; (b) recebimentos de caixa de retornos sobre empréstimos, outros instrumentos de endividamento de outras entidades e ações do patrimônio; e (c) todos os outros recebimentos de caixa que não provêm de transações definidas como atividades de financiamento ou investimento, como os montantes recebidos de questões judiciais.

Para os mesmos autores as saídas de caixa das atividades operacionais são: (a) pagamentos de caixa para aquisição de materiais para manufatura ou bens para revenda; (b) pagamentos de caixa para outros fornecedores e empregados por outros bens ou serviços; (c) pagamentos de caixa aos governantes por impostos, taxas, contribuições ou outras multas; (d) pagamentos de caixa para emprestadores e outros credores pelos juros; e (e) todos os outros pagamentos de caixa que não provêm de transações definidas como atividades de investimento e financiamento, como pagamentos para questões judiciais, contribuições em dinheiro para caridade e caixa restituído aos clientes. 


\section{Fluxo de Caixa de Investimentos}

De acordo com Gitman (2010), os fluxos de investimentos representam a compra e venda de ativos imobilizados e investimentos de participações societárias que resultam em saídas de caixa e de vendas.

O CPC 03 R2, de 2016, ressalta a importância da atividade de investimento para o fluxo de caixa, afirmando que os mesmos são feitos pela entidade com a finalidade de gerar lucros e fluxo de caixa no futuro.

\section{Fluxo de Caixa de Financiamentos}

No CPC 2016, as atividades de financiamento são definidas como as que resultam em mudanças no tamanho e na composição do capital próprio e de terceiros da empresa.

Conforme Gitman (2010), os fluxos de caixa de financiamentos são oriundos de transações financeiras utilizando o capital de terceiros ou próprio. Assim, podemos entender que atividades de financiamento são aquelas que resultam das alterações no tamanho e na composição do patrimônio líquido e, ainda, dos empréstimos da empresa.

\section{GESTÃO FINANCEIRA}

A Gestão Financeira é imprescindível para o sucesso e sustentabilidade das empresas que buscam se manter no mercado. Ela dedica-se ao estudo das decisões financeiras assumidas na empresa, sendo caracterizada como um conjunto de ações e procedimentos administrativos que envolvem o planejamento, o controle e a análise das atividades econômicas e financeiras da empresa. (DAL-RY, 2009).

A Gestão financeira pode ser definida como a gestão dos fluxos monetários derivados da atividade operacional da empresa, em termos de suas respectivas ocorrências no tempo. Ela objetiva encontrar o equilíbrio entre a "rentabilidade" (maximização dos retornos dos proprietários da empresa) e a "liquidez" (que se refere à capacidade de a empresa honrar seus compromissos nos prazos contratados). (CHENG e MENDES, 1989).

Faz-se necessário entender que a Gestão Financeira de uma empresa não se limita à negociação de prazos e de juros de uma transação de investimento. Cabe ao gestor financeiro a preocupação com os recursos financeiros, no que tange a obtenção, análise e controle dos mesmos, assim como a avaliação dos resultados econômicos provenientes de suas decisões.

A princípio, o planejamento financeiro estratégico contribui com a maximização dos lucros e a operacionalidade das atividades corriqueiras de uma empresa. Assim, podemos 
entender que está imposta na Gestão Financeira a procura pela paridade entre gerar lucros e manter o caixa da empresa, isto é, este modelo de gestão estabelece relação com o controle de entradas e saídas oriundas dos recursos gerados das atividades operacionais do estabelecimento empresarial.

\section{Planejamento Financeiro}

De acordo com Trindade Júnior (2009), o homem sentiu a necessidade de se preparar para o futuro e, com o passar do tempo, avançou em seus conhecimentos, desenvolvendo habilidades na intensão de conquistar melhorais em sua condição de vida. Então, sutilmente, a ideia de planejamento já estava inserida em suas atitudes, uma vez que, para caçar e pescar, por exemplo, era necessário escolher o equipamento ideal, verificar e analisar as condições climáticas, fazer reconhecimento do local, entre outras ações. Assim, podemos perceber que o planejamento já existia desde a pré-história.

Durante as décadas de 50 e 60, o planejamento financeiro predominava acima de qualquer outro tipo de planejamento, pois havia o orçamento - utilizado como instrumento de controle e operacionalização de gestão. Havia uma preocupação com os gastos para o futuro próximo, e, baseados nas movimentações do ano anterior, era elaborada uma previsão para o ano seguinte. Porém, não havia mobilização para ganhar mercado, manter clientela ou inovar serviços e produtos. Todos os esforços eram voltados para a questão financeira, apesar de ser justificável esta forma de atuar, pois, nessa época, as mudanças na sociedade e seus costumes eram muito lentas, o que proporcionava às empresas bem-sucedidas a conseguirem realizar os investimentos e obter a rentabilidade desejada. (TAVARES, 2009).

\section{METODOLOGIA}

A pesquisa foi distribuída em quatro fases distintas com avaliações cruzadas entre elas. A primeira fase buscou o conhecimento teórico referente à contextualização do objeto de estudo; a segunda fase foi composta de um questionário aplicado aos funcionários do empreendimento, visando identificar o momento e os motivos que levaram a empresa à atual situação; a terceira fase teve por objetivo observar o funcionamento do bar no que diz respeito à clientela, satisfação dos clientes, rotatividade de mercadorias e a relação oferta-procura. Ainda nesta fase, foi feito o uso de planilhas para registro de dados necessários para um diagnóstico mais preciso. 
A quarta e última etapa foi a leitura das fases dois e três, com base nos conhecimentos adquiridos na primeira fase, e apresentação dos resultados encontrados, com as propostas de soluções para os problemas existentes.

A pesquisa aconteceu entre outubro de 2018 e março de 2019.

\section{ESTUDO DE CASO}

A situação político-social do país nos últimos anos levou muitas empresas, principalmente as de pequeno porte, à decadência. Entre elas, a empresa que é o campo de pesquisa do presente trabalho. Trata-se de um Barzinho que, por questão de ética, terá seu nome poupado, utilizando, para isso, o nome fictício de Esquina's Bar - MEI. O barzinho, de ambiente familiar, administrado pelo próprio proprietário (com o auxílio de sua mãe, filhas e genro), está localizado no bairro de Piedade, na Cidade de Jaboatão dos Guararapes - PE.

O funcionamento da empresa dá-se de terça-feira a domingo, sendo fechado nas segundas-feiras. O público que frequenta o estabelecimento é altamente diversificado em relação à idade, gênero e classe social.

Atualmente, a empresa oferece almoço comercial, bebidas diversas (alcoólicas e não alcoólicas), petiscos e música ao vivo nos finais de semana.

A empresa, antes da interferência deste estudo, não tinha conhecimento real do seu faturamento, tendo em vista que não contavam com nenhum tipo de controle de entradas e saídas, nem do estoque, nem de numerários. No entanto, ao final desta pesquisa, o faturamento cresceu gradativamente, atingindo um faturamento médio de $\mathrm{R} \$ 30.000,00$ (trinta mil reais) mensais.

\section{Análise e Resultado da Pesquisa}

No decorrer da pesquisa, foram coletadas e analisadas informações que auxiliaram na caracterização do universo que constitui o presente Estudo de Caso. Foram identificadas as causas que estavam levando o estabelecimento comercial à falência, além de apresentar as possibilidades de reorganização das finanças e a reversão do quadro.

A análise foi realizada através da comparação de conceitos teóricos com experiências relatadas, assim como a observação e o acompanhamento próximo e direto, correlacionando as informações encontradas, a fim de localizar e solucionar a problemática existente. 
A Tabela 1 apresenta o fluxo de caixa do Esquina's Bar, referente aos desembolsos e ingressos à vista e a prazo.

Observando as informações contidas no fluxo de caixa abaixo, nota-se uma flutuação em relação à porcentagem de vendas a prazo. Segundo o proprietário do bar, isso se deve à época do ano em que a pesquisa foi realizada. Ele afirma, ainda, que nos meses de maio até setembro, normalmente, as vendas no cartão tendem a baixar e as vendas à vista, aumentam.

Apesar do fluxo de caixa mostrar todos os saldos negativos, observa-se que, até o final desta pesquisa, o mesmo obteve um crescimento de mais de $67 \%$, o que nos mostra que, mantendo-se tal padrão, dentro de quatro ou cinco meses o bar poderá fechar cada mês futuro com saldo positivo superior a $\mathrm{R} \$ 15.000,00$.

Ao evidenciar ao proprietário como é feito um fluxo de caixa, obedecendo à literatura, o mesmo respondeu que nunca havia feito um controle minucioso e detalhado das entradas e saídas do bar. Ele revelou que não sabia ao certo o que recebia e o que pagava, nem ao menos se estava tendo lucro ou prejuízo. Às vezes havia um movimento grande, tudo era vendido, mas não sabia para onde o dinheiro ia. O proprietário passou a acreditar que o fluxo de caixa poderia melhorar o gerenciamento do bar e ajudar a projetar para datas futuras, assim como assessorar no planejamento e controle das atividades. Através dos resultados obtidos com essa simples ferramenta, sem custos para o bar, percebemos o quão essencial ela é no auxílio do controle de vendas e despesas.

É possível observar, claramente, que a falta de controle e conhecimento administrativo/financeiro levou a empresa ao declínio.

Tabela 1. Fluxo de Caixa do Esquina's Bar

\begin{tabular}{|c|c|c|c|c|c|}
\hline \multicolumn{6}{|c|}{ ESQUINA'S BAR } \\
\hline \multicolumn{6}{|c|}{ FLUXO DE CAIXA } \\
\hline HISTÓRICO & $\begin{array}{c}\text { Outubro } \\
2018\end{array}$ & $\begin{array}{c}\text { Novembro } \\
2018\end{array}$ & $\begin{array}{c}\text { Dezembro } \\
2018\end{array}$ & $\begin{array}{c}\text { Janeiro } \\
2019\end{array}$ & $\begin{array}{c}\text { Fevereiro } \\
2019\end{array}$ \\
\hline \multicolumn{6}{|c|}{ INGRESSOS DE RECURSOS FINANCEIROS } \\
\hline$(+)$ Recebimentos de Clientes à vista & $16.250,00$ & $19.321,00$ & $40.236,00$ & $9.210,00$ & $21.130,00$ \\
\hline (+) Recebimentos de Clientes no Cartão & $8.100,00$ & $18.000,00$ & $13.235,00$ & $24.037,00$ & $20.000,00$ \\
\hline (-) Pagamentos a Fornecedores & $(2.220,80)$ & $(2.220,80)$ & $(2.220,80)$ & $(2.220,80)$ & $(2.220,80)$ \\
\hline (-) Despesas (Vendas, adm. e gerais) & $(4.800,00)$ & $(5.150,00)$ & $(4.300,00)$ & $(4.750,00)$ & $(3.850,00)$ \\
\hline $\begin{array}{l}(=) \text { Ingressos Provenientes das } \\
\text { Operações }\end{array}$ & $17.329,20$ & $29.950,20$ & $46.950,20$ & $26.276,20$ & $35.059,20$ \\
\hline
\end{tabular}




\begin{tabular}{|c|c|c|c|c|c|}
\hline (+) Ingresso de Novos Empréstimos & $10.000,00$ & 0,00 & 0,00 & 0,00 & 0,00 \\
\hline (=) Total de Ingressos de Rec. Fin.(A) & $27.329,20$ & $29.950,20$ & $46.950,20$ & $26.276,20$ & $35.059,20$ \\
\hline \multicolumn{6}{|c|}{ DESTINAÇÃO DE RECURSOS FINANCEIROS } \\
\hline (+) Aquisição de Utensílios / Reforma & $1.425,00$ & $1.425,00$ & $1.425,00$ & $1.425,00$ & $1.425,00$ \\
\hline$(+)$ Pagamentos de Empréstimos & $3.677,50$ & $3.077,50$ & $3.077,50$ & $2.577,50$ & $2.577,50$ \\
\hline$(+)$ Compras à vista & $8.370,00$ & $16.500,00$ & $10.194,00$ & $7.138,00$ & $7.534,00$ \\
\hline (+) Pagamentos de Dividendos & $1.000,00$ & $1.000,00$ & $1.000,00$ & $1.000,00$ & $1.000,00$ \\
\hline $\begin{array}{l}\text { (=)Total das Destinações de Rec. Fin. } \\
\text { (B) }\end{array}$ & $14.472,50$ & $22.002,50$ & $15.696,50$ & $12.140,50$ & $12.536,50$ \\
\hline C (=A-B) Variação Líquida de Caixa & $12.856,70$ & $7.947,70$ & $31.253,70$ & $14.135,70$ & $22.522,70$ \\
\hline D (=) Saldo de Caixa Inicial & $(132.503,00)$ & $(119.646,30)$ & $(111.698,60)$ & $(79.644,90)$ & $(65.509,20)$ \\
\hline$(=C+D)$ Saldo de Caixa Final & $(119.646,30)$ & $(111.698,60)$ & $(80.444,90)$ & $(65.509,20)$ & $(42.986,50)$ \\
\hline
\end{tabular}

Fonte: as autoras (2019)

\section{CONSIDERAÇÕES FINAIS}

Este artigo teve por objetivo analisar, através de um estudo de caso, a importância, eficiência e efetividade do Fluxo de Caixa como instrumento de gestão, planejamento e controle, auxiliando na tomada de decisões em um bar.

No início da pesquisa foi constatado que a empresa, além de não fazer uso de nenhuma ferramenta para controle financeiro, ainda mantinha as finanças pessoais e domésticas, de toda a família, misturadas com a do estabelecimento comercial. Dessa forma, era impossível definir como estava a real situação da empresa, adquirir credibilidade de clientes e fornecedores, dificultando nas negociações de créditos e dívidas, consequência de tomadas de decisões sem embasamento.

A primeira atitude, e mais difícil, foi desvencilhar as finanças. O proprietário foi levado a entender que o bar é um ente a parte, com entradas e saídas próprias de numerários e que, para identificar o problema e estimar o tamanho do mesmo, fazia-se necessário tal separação.

No início, foi difícil adaptar-se ao uso do fluxo de caixa, esquecendo, por várias vezes, de tomar nota de algumas saídas e entradas de numerários. Porém, ao conseguir mecanizar o processo, foram observados os principais tipos de entradas e saídas de caixa, as saídas que 
podiam ser evitadas ou proteladas, assim como o quanto a empresa podia investir e pagar dívidas de curto e longo prazo, mantendo o controle financeiro.

Nos cinco meses da pesquisa, o bar finalizou com saldos de caixa negativos. Isso se deve ao fato de seu proprietário ter adquirido vários empréstimos com dois bancos, alguns amigos e nove agiotas.

Foram feitos acordos com os agiotas para que cessassem os juros e dividissem o saldo devedor do momento. Alguns, de baixo valor, foram quitados até o término desta pesquisa. Outros, com valores de $\mathrm{R} \$ 5.000,00$ até $\mathrm{R} \$ 25.000,00$, foram parcelados em até 25 vezes iguais.

Foram negociadas, também, dívidas com alguns fornecedores. Todas elas, independente dos valores, foram parceladas em dez vezes iguais. As compras passaram a ser realizadas à vista.

No início da intervenção para o desenvolvimento desta pesquisa, o bar não contava com um estoque, sendo realizadas compras diárias e, na maioria das vezes, por preços altos. Daí, a necessidade de organizar o estoque. Para isso, foi ejetado o valor de R\$10.000,00 em compras, o qual configurou, no fluxo de caixa, como Ingresso de Novos Empréstimos.

Através da utilização do fluxo de caixa, o proprietário pôde estabelecer novas metas e desenvolver, juntamente aos seus colaboradores, estratégias que aumentaram significativamente as entradas dos recursos financeiros por consequência do aumento das vendas.

Este estudo possibilitou comprovar a eficiência e eficácia do uso do fluxo de caixa como ferramenta de gestão, organização e controle.

\section{REFERÊNCIAS}

BRAGA, R.; MARQUES, J. A. Avaliação da liquidez das empresas através da análise da demonstração de fluxos de caixa. Revista Contabilidade \& Finanças. 2001. Disponível em: http://www.scielo.br/scielo.php?script=sci_arttext\&pid=S151970772001000100001\&lang=pt. Acesso em: 14 dez. 2018.

BRASIL. Lei Federal $\mathbf{N}^{\mathbf{0}}$ 11.638, de 28 de dezembro de 2007. Altera e revoga dispositivos da Lei $n^{\circ}$ 6.404, de 15 de dezembro de 1976, e da Lei ${ }^{\circ} 6.385$, de 7 de dezembro de 1976, e estende às sociedades de grande porte disposições relativas à elaboração e divulgação de demonstrações financeiras. Disponível em: http://www.planalto.gov.br/ccivil_03/_Ato20072010/2007/Lei/L11638.htm. Acesso em: 02 dez. 2018. 
CHENG, Ângela, MENDES, Marcia Martins. A importância e a responsabilidade da gestão financeira na empresa. Trabalho apresentado na XVIII Conferência Interamericana de Contabilidade - 1989 - $\quad$ Paraguai. Disponível em: http://www.scielo.br/scielo.php?pid=S1413-92511989000100002\&script=sci_arttext. Acesso em: 15 dez. 2018.

DAL-RY, Sivaldo. Como Fazer Administração Financeira. Comunidade ADM. Disponível em: $\quad$ http://www.administradores.com.br/artigos/negocios/como-fazer-administracaofinanceira/32618/. Acesso em: 15 dez. 2018.

FARIA, José Carlos. Administração - Introdução ao Estudo. São Paulo: Pioneira, 1994.

GITMAN, Lauwrence J. Princípios da administração financeira: 10. ed. São Paulo: Pearson, 2004.

MARION, José Carlos. Contabilidade Básica. 8. ed. São Paulo: Atlas, 2008.

RIBEIRO, Osni Moura. Contabilidade Intermediária. 3. ed. São Paulo: Saraiva, 2009.

SANTI FILHO, Armando de. Análise do demonstrativo de Fluxo de Caixa. 2. ed. São Paulo: Santi, 2004.

SANTOS, Edno Oliveira dos. Administração financeira da pequena e média empresa. São Paulo: Atlas, 2001.

TAVARES, Mauro Calixto. Gestão Estratégica. 3. ed. São Paulo: Atlas, 2010.

TRINDADE JÚNIOR, Francisco Ulisses da. Planejamento das licitações: o planejamento das licitações públicas como fator de eficiência. BDJur, Brasília, DF. 22 jan. 2009. Disponível em:http://bdjur.stj.jus.br/dspace/handle/2011/26736. Acesso em: 16 dez. 2018.

ZDANOWICZ, José Eduardo. Fluxo de caixa: uma decisão de planejamento e controle financeiro. 9. ed. Porto Alegre: Editora Sagra Luzzatto, 2002. 


\section{APÊNDICE A - QUESTIONÁRIO PARA DIAGNÓSTICO}

(Aplicado ao proprietário)

\section{PARTE 1: IDENTIFICAÇÃO DO ENTREVISTADO}

1) Sexo

2) Idade

3) Há quanto tempo você possui este empreendimento?

\section{PARTE 2: PROPÓSITO}

1) Para você, quais os objetivos desta empresa?

2) Quem determina os objetivos desta empresa?

3) Qual a meta desta empresa?

4) Você acredita que os objetivos seguem ligados com a meta desta empresa?

5) Qual o giro comercial desta empresa?

6) Você conta com o auxílio dos seus colaboradores nas decisões desta empresa?

\section{PARTE 3: ESTRUTURA}

1) Esta empresa possui registro perante os órgãos competentes?

2) Esta empresa está em dia com todos os impostos e obrigações sociais?

3) A empresa funciona em prédio próprio?

4) Qual a estrutura desta empresa?

5) Qual o organograma desta empresa?

6) Você considera os colaboradores como parte da estrutura desta empresa?

7) Existem níveis hierárquicos na empresa? Se sim, quais são?

8) Você conta com o auxílio de um profissional de contabilidade na empresa?

9) Como você descreve a atual situação econômico/financeira desta empresa?

\section{PARTE 4: RELACIONAMENTOS INTERNOS}

1) Você se sente motivado a trabalhar aqui?

2) As outras pessoas que trabalham aqui te apoiam na realização de suas tarefas?

3) Em caso de problemas, você conta com o auxílio de alguém para tomar decisões?

4) Costuma ser você quem resolve problemas com clientes?

5) Apesar de existir parentesco entre os companheiros de trabalho, a relação profissional é satisfatória?

6) Existe divisão entre a vida pessoal e profissional dos que trabalham na empresa?

7) Existe divisão de alimentos e bebidas entre o que é para venda e a para o consumo da família?

\section{PARTE 5: RECOMPENSAS}

1) Você é remunerado pelo seu trabalho nesta empresa?

2) O que te incentiva a permanecer realizando suas atividades?

3) Existe uma equidade de recompensa entre as pessoas que trabalham nesta empresa? 


\section{PARTE 6: LIDERANÇA}

1) Quem atua como líder nesta empresa?

2) O líder cria um ambiente de trabalho propício?

3) O líder compartilha informações sobre a empresa?

4) O líder pede opinião aos outros colaboradores?

5) O líder estaria disposto a passar a liderança para um de seus colaboradores sem, contudo, deixar de auxiliar e desempenhar as demais atividades?

\section{PARTE 7: MECANISMOS AUXILIARES}

1) A empresa utiliza algum meio para processar as informações comerciais? Se sim, quais?

2) Você conta, SEMPRE, com todas as ferramentas necessárias para desempenhar suas atividades?

3) Existe um planejamento para o futuro desta empresa?

4) Existe algum método para medir a qualidade do trabalho?

5) Você sabe como fazer mudanças para melhorar o seu trabalho e assim cumprir com os objetivos desta empresa?

6) Quais dos itens abaixo esta empresa faz uso?

$\square$ Livro caixa

$\square$ Comandas de pedidos

$\square$ Controle de estoque

$\square$ Controle de sobras

$\square$ Controle de pagamentos

$\square$ Acompanhamento de fornecedores

$\square$ Propaganda

\section{PARTE 8: CONTROLE FINANCEIRO}

1) Quanto você gasta na compra de insumos para a produção?

2) Quanto seus clientes pagaram ao longo deste mês?

3) Qual é o seu gasto com a folha de pagamento dos seus funcionários?

4) Quais despesas para manutenção do estabelecimento você tem todo mês (água, luz, telefone, aluguel do ponto, limpeza, outros...)?

5) Quais impostos você precisa pagar?

6) Quais taxas são cobradas quando o cliente paga com cartão e quanto você "perde" do pagamento? 


\section{APÊNDICE B - QUESTIONÁRIO PARA DIAGNÓSTICO}

(Aplicado aos parentes que auxiliam no bar)

\section{PARTE 1: IDENTIFICAÇÃO DO ENTREVISTADO}
4) Sexo
5) Idade
6) Qual a sua relação com o proprietário deste estabelecimento?
7) Há quanto tempo você trabalha aqui?
8) Qual a sua função na empresa?

\section{PARTE 2: PROPÓSITO}

7) Para você, quais os objetivos desta empresa?

8) Você concorda com os objetivos desta empresa?

9) Qual a meta desta empresa?

10) Você acredita que os objetivos seguem ligados com a meta desta empresa?

11) Você conhece o giro comercial desta empresa?

12) Você opina nas decisões desta empresa?

\section{PARTE 3: ESTRUTURA}

10) Você conhece a estrutura desta empresa?

11) Você conhece o organograma desta empresa?

12) Você se sente parte da estrutura desta empresa?

13) Para você, existem níveis hierárquicos na empresa? Se sim, quais são?

14) Existem outras pessoas que realizam a mesma tarefa que você? Se sim, eles se encontram no mesmo nível hierárquico que você?

15) Os objetivos desta empresa estão ligados com a tarefa que você desempenha?

\section{PARTE 4: RELACIONAMENTOS INTERNOS}

8) Você se sente motivado(a) a trabalhar aqui?

9) As outras pessoas que trabalham aqui lhe apoiam na realização de suas tarefas?

10) Em caso de problemas, a quem você se dirige?

11) Você costuma resolver problemas com clientes?

12) Apesar de existir parentesco entre os companheiros de trabalho, a relação profissional é satisfatória?

13) Existe divisão entre a vida pessoal e profissional dos que trabalham na empresa?

14) Existe divisão de alimentos e bebidas entre o que é para venda e a para o consumo da família?

\section{PARTE 5: RECOMPENSAS}

4) Você é remunerado(a) pelo seu trabalho nesta empresa?

5) Existem incentivos para que você permaneça realizando suas atividades?

6) Você concorda com a maneira e os incentivos como é recompensado(a)?

7) Os objetivos da empresa estão ligados com a forma de recompensa? 
8) Existe uma equidade de recompensa entre as pessoas que trabalham nesta empresa?

\section{PARTE 6: LIDERANÇA}

6) Quem atua como líder nesta empresa?

7) Qual a sua relação com o líder?

8) O líder cria um ambiente de trabalho propício?

9) O líder compartilha informações sobre a empresa?

10) O líder pede sua opinião?

11) O líder te sugere ideias que contribuam com as atividades desempenhadas por você?

\section{PARTE 7: MECANISMOS AUXILIARES}

7) A empresa utiliza algum meio para processar as informações comerciais?

8) Você conta, SEMPRE, com todas as ferramentas necessárias para desempenhar suas atividades?

9) Existe um planejamento para o futuro nesta empresa?

10) Você participa do planejamento desta empresa, apontando ideias?

11) Existe algum método para medir a qualidade do seu trabalho?

12) Você sabe como fazer mudanças para melhorar o seu trabalho e assim cumprir com os objetivos desta empresa? 